\title{
O que é a Neuroantropologia Afinal? Consideraçóes e Contribuiçóes de uma Ciência Pouco Conhecida
}

\author{
What is Neuroanthropology? Considerations and Contributes of an Poorly Known Science \\ Otávio Barduzzi Rodrigues da Costa
}

\section{RESUMO}

Este artigo científico tem como objetivo trazer contribuições de uma ciência empírica de caráter interdisciplinar, a Neuroantropologia. Nesse trabalho, são discutidos alguns dados e conjecturas da Neuroantropologia, que ainda não tem muita representatividade no Brasil ou mesmo no mundo. Embora exista a Sociedade Internacional de Neuroantropologia, e seja uma ciência que possa cooperar muito para o crescimento das neurociências, a neuroantropologiatem a capacidade de explicitar certos assuntos relativos a essa ciência multidisciplinar em expansão bem como oferecer certas explicaçôes médicas de distúrbios cognitivos. O objetivo deste artigo, longe de poder esgotar o tema, quer apenas mostrar as possíveis contribuiçóes daneuroantropologia que ainda é incipiente dentro dos campos da neurociências.

Unitermos. Ciência Cognitiva, Neurociências, Antropologia.

Citaçáo. Costa OBR. O que é a Neuroantropologia Afinal? Consideraçóes e Contribuições de uma Ciência Pouco Conhecida.

\begin{abstract}
This paper intends to explain the contributions of Neuro-anthropology. In this work, will be propose some data and conjectures of Neuroanthropology, that it is not much representative in Brazil, or in the hole world. Although exists the Neuro-Anthropology International Society, and it is a science that can cooperate to the growth of neuroscience, it can clarify some matters relating to this multidisciplinary science and provide certain medical explanations of cognitive disorders. The purpose of this articleisnot to exhaust the topic,it is just to show the possible contributions of Neuro-Anthropologythat is still incipient in the fields of neuroscience.
\end{abstract}

Keywords. Cognitive Science, Neuroscience, Anthropology.

Citation. Costa OBR. What is Neuroanthropology? Considerations and Contributes of an Poorly Known Science.
Trabalho desenvolvido em USC, Bauru-SP, Brasil.

1.Antropólogo físico, Doutorando em Comunicação e Cognição pela Metodista, Professor da UNESP-FAAC, professor de antropologia física do curso de pós-graduação em antropologia da USC, jurista pela ITE - Bauru-SP, Brasil.
Endereço para correspondência: Av. Bispo Cesar Dacorso Filho, 691, Rudge Ramos, CEP 09607-000, São Bernardo do Campo-SP, Brasil. E-mail: joebarduzzi@yahoo.com.br 
A Neuroantropologia tem como preocupação principal estudar a neuro-evolução do sistema nervoso do homem embora não se limite apenhas isso. É uma ciência multidisciplinar que consiste em estudar as relaçóes do sistema nervoso humano com os diversos aspectos dos seres humanos. Envolve estudos de comportamento e sua relação com o sistema neural, doenças mentais, relaçóes sociais dos doentes mentais, questões antropológicas de saúde mental e outros aspectos.

A neuroantropologia cognitiva consiste em um dos ramos da bioantropologia que estuda os mecanismos de evolução biológica, herança genética, adaptabilidade e variabilidade humana, primatologia e compila o registro fóssil da evolução do sistema nervoso humano. A neuroantropologia cognitiva analisa o processo da evolução biológica do cérebro humano, através de estudos dos crânios de homens e hominídeos; da adaptabilidade de populaçóes extintas e realiza sua comparação com as não extintas; do apontamento da localização de estruturas cerebrais que existem em fósseis, da primatologia cerebral comparada a hominídeos e registro de crânios fossilizados.

Ainda em primeiro lugar faz-se necessário definir alguns conceitos de antropologia tradicional: Antropologia é a ciência reflexão, teoria, sobre a humanidade e sua cultura, tendo como objetivo o estudo completo sobre o homem ${ }^{1}$.

Como ciência do biológico e do cultural tem como objeto de estudo o homem e sua evolução,esse ramo da antropologia é chamado ora de antropologia física, tendo esse termos preferência entre autores norte-americanos, ora de antropologia biológica pelos europeus, hodiernamente é chamada de bioantropologia ${ }^{2}$. Estuda a natureza física do homem, conhecendo suas origens e evoluçôes, estrutura anatômica e fisiológica, por exemplo: o estudo do homem fóssil, suas mudanças evolutivas, sua anatomia e suas produçóes culturais.

A neuroantropologia estuda essa múltipla complexidade do ser humano no que é relativo ao seu cérebro sistema nervoso. Muita informação fica registrada nos ossos transformando estes na pista mais direta do quotidiano dosantepassados humanos.

Aneuroantropologia cognitiva estuda as relações entre alteraçóes corporais e cerebrais, no processo da evolução biológica. Tem como objetivo explicar os proces- sos neurocognitivos do o que é considerado como propriamente humano tais como compreensão de símbolos, orientação diferenciada do ser humanos, uso diferenciado de tecnologia, capacidade de design, de destreza e apontar as capacidades cerebrais de ascendentes do homem e de outras habilidades.

Visa analisar um dos mais interessantes manifestações da vida: a cognição humana. Também pode contribuir com explanaçóes teóricas da psicologia, neurologia, psiquiatria, ciências cognitivas e neurociência em geral.

A neuroantropologia ganhou destaque nos anos 1970, quando Oliver Sacks, professor de neurologia da Escola de Medicina Albert Einstein da Universidade de Nova York, começou a trabalhar também como neurologista, no Hospital Berth Abraham, no Bronx, em Nova York, onde trabalhou com pacientes que se caracterizavam, por estarem há décadas, em estado catatônico, incapazes de qualquer tipo de movimento (este caso inspirou-o a escrever, em 1973, o livro Awakenings, retratado no filme "Tempo de Despertar") ${ }^{3}$.

Dez anos depois, Oliver Sacks constatou que esses doentes eram sobreviventes e descendentes de portadores de uma grande epidemia da doença do sono que assolou o Alasca, entre 1916 e 1927. Tratou-os então com um medicamento novo, A $L$-dopa, que permitiu que eles aos poucos regressassem a vida normal ${ }^{4}$.

A Universidade de Nova York realizou pesquisa multidisciplinar entre os cursos de medicina e antropologia, analisando os crânios dos antecedentes de algumas vítimas daquele estado catatônico, constatando que havia pequenas diferenças (anomalias) nos lóbulos laterais cerebrais esquerdos, patologia também encontrada em necropsias dos pacientes desse mesmo caso ${ }^{3}$.

Essas diferenças foram intuídas no sentido de que havia uma marca diferenciada no crânio das pessoas que pressupunha através de modelagem cerebral ter existido uma anomalia, como uma protuberância irregular nos lóbulos laterais cerebrais esquerdos. Descobrindo tais anomalias pode dar respostas mais completas sobre aquele surto de doença isso graças à neuroantropologia ${ }^{3}$.

Pode ainda explicar questóes como porque certas doenças surgiram durante o processo evolutivo, algo muito importante desse processo foram às novas fontes de alimentação possibilitada pelos usos de instrumentos 
e de caça, o que afetou nossa fonte de neuroquímica. $\mathrm{O}$ acesso a uma grande fonte de carne pôde possibilitar uma nova fonte de carbono e fósforo tendo como consequência a possibilidade de hiperfosforilação da proteina TAU e excesso de acetilcolina que afetam o equilíbrio celular em Alzheimer. Ainda com o uso de armas e descoberta do fogo boa parte do medo de animais se perdeu, o que causou diminuição da noradrenalina e também afeta $o$ equilíbrio neurocelular ${ }^{5}$.

Pesquisar a evolução neurobiológica humana pode explicar muita coisa da sociabilidade e psique social e linguagem, bem como apontar as bases neuro evolutivas da aprendizagem diferenciada humana.

Um dos tópicos mais interessantes da neuroantropologia é o estudo da evolução do trabalho humano, suas relaçóes com as atividades corporais, o desenvolvimento cerebral e a evolução das ferramentas cognitivas tais como a inteligência. Além disso, ainda pode estudar dentro da sua ampla gama de alcance de outros tópicos igualmente relevantes, tais como: as influências dos fatores biológicos, como o desenvolvimento do aparelho neuropalatal e as aquisiçóes neurais provindas da neotenia; as alteraçóes dos fatores comportamentais, influenciados pela adoção do bipedalismo; as relaçóes de socialização; a linguagem; a estratégias de caça e outros.

Pode dar respostas de como o cérebro evoluiu e as condições que se formaram certas partes do cérebro como o neo córtex frontal, e associar essa área que é responsável pelas atividades próprias do ser humano (imaginação, sonho, alucinação, etc...).

Modernas técnicas de arqueologia podem remodelar um cérebro com alto grau de certeza utilizando a remodelação a laser que consiste em sistematizar um modelo de um crânio real achado e através de ligação entre pontos pode modular com alta precisão os órgãos que estavam dentro daqueles fósseis, inclusive o cérebro, outra técnica muito usada é amodelagem computacional tri-dimensional ${ }^{6}$, que consiste em utilizar de softwares específicos para modelar órgãos de fósseis ${ }^{7}$.

Com tais tecnologias de modelação é possível levantar a modelagem de áreas que foram aparecendo a cada passo evolutivo humanoe no órgão mais complexo - o cérebro, seu formato bem como as áreas especificas de crescimento cerebral através da evolução humana, por exemplo, datar em que época e condiçóes surgiu a área de Broca, utilizando essas novas técnicas em cérebros de ancestrais humanos ${ }^{8}$.

Hoje em dia com novas técnicas inicialmente para a arqueologia e antropologia os neuroantropologos podem determinar com certo grau de precisão em que ponto da historia evolutiva surgiu certas áreas cerebrais e ajudar a explicar certos comportamentos e problemas de saúde dos humanos.

Nos primatas superiores, o neocórtex atingirá proporçóes gigantescas tais que, para caber na caixa craniana, terá que se preguear e se desdobrar, gerando, assim, as circunvoluçôes. No homem, vai predominar o crescimento dos lobos frontais e temporais, com o desenvolvimento especial da área pré-frontal, cujas estruturas fornecem o substrato anatomobiológico para as funções mais complexas do ser humano, inclusive algumas que parecem ser da absoluta exclusividade da espécie, como a destreza para uso e fabricação de tecnologia, rituais e crença em algo que não estão aparente (um suposto mundo espiritual) ${ }^{9}$.

Ao analisar a evoluçáo cerebral (dos austrelopithecus ao homo sapiens sapiens) dos ascendentes do gênero humano, percebe-se um amplo grau de mudança cerebral enquanto o cérebro dos primeiros austrelopithecus pesam cerca de $400 \mathrm{gr}$ o do homem moderno atinge a marca de $1,4 \mathrm{~kg}$, alem de estruturas como o neo-cortex frontal exclusivo no homo sapiens sapiens ${ }^{8}$, podemos responder algumas das perguntas que fazemos desde o inicio da filosofia - porque o homem tem auto - consciência, porque é capaz de linguagem, de construir ferramentas? Dentre outras habilidades cognitivas.

Por exemplo, se hoje podemos observar e conhecer detalhadamente todo o bipedalismo (processo pelo qual os descendentes do homem abandonaram as arvores, e ficaram sobre duas pernas) e sabemos que tal processofoi fundamental para o desenvolvimento diferenciado da cogniçáo humana, pois ele foi causa do aumento do cérebro, da sociabilidade e outros fatores que caracterizam a cognição humana'.

Essa maneira única de andar,o bipedalismo apareceu nos primeiros ancestrais humanos do gênero Australopithecus, há cerca de quatro milhões de anos. A despeito da postura ereta, os Australopithecus típicos não passavam do $1,2 \mathrm{~m}$ de altura e seus cérebros não eram muito maio- 
res do que os dos chimpanzés ${ }^{9}$. Evidências paleontológi$\operatorname{cas}^{10}$ recentes levantaram a questão sobre qual das várias espécies de Australopithecus fazia parte da linhagem que levou ao Homo.

A expansão mais significativa do cérebro de adultos e bebês ocorreu depois dos Australopithecus, em particular no gênero Homo. O fóssil Noriokotome, do Quênia, de 1,5 milhão de anos de idade, é um adolescente, frequentemente, chamado de Turkanaboy. Pesquisadores estimaram que os parentes adultos do garoto, provavelmente, possuíam cérebros cerca de duas vezes maiores em relação à dos Australopithecus ${ }^{11}$.

Neuroantropologos testam (e a maioria concorda), atualmente, uma importante hipótese diz que a anatomia pélvica dos primeiros Homo pode ter limitado o crescimento do cérebro humano até o estágio evolucionário em que o canal de nascimento expandiu-se o bastante para permitir a passagem de uma cabeça de bebê maior. Essa afirmação implica que, a partir da neotenia vai haver o aumento acentuado no tamanho do cérebro humano fora do útero, o que poderá causar profudas mudanças cognitivas, e o ser humano é único nesse nível pois seus cérebros aumentam $60 \%$ até a vida adulta enquanto os macacos apenas $10 \%$, ocorrido de dois milhóes a cem mil anos atrás ${ }^{12}$.

Fósseis que abarcam os últimos 300 mil anos de evolução humana dão suporte à conexão entre a expansão do tamanho do cérebro e as mudanças na anatomia pélvica. Nos últimos 20 anos, cientistas encontraram três fósseis de Homo sapiens arcaico: um macho em Sima de los Huesos, na Sierra Atapuerca, na Espanha, com mais de 200 mil anos de idade; uma fêmea em Jinniushan, na China, com 280 mil anos; e o macho Kebara Neandertal, em Israel, com cerca de 60 mil anos $^{13}$.

Simplesmente por causa da posição em pé, o cérebro hominídeo teve de crescer exteriormente ao corpo, isso porque a pelve do ser feminino do Australopithecus não suportaria uma passagem de cabeça já pronta e grande, e por ter afinado a passagem de um cérebro pronto, para isso o filhote teve deproporcionando um cérebro diferente de outros seres vivos. Isso simplesmente teve de acontecer para a sobrevivência hominídea. Tal crescimento possibilitou uma novidade genuína na natureza: um cérebro complexo dotado de um crescimento de estru- turas exclusivas do gênero Homo tais como: um lóbulo frontal, um fascículo arqueado e área de Wernick (associados à destreza) e área de Broca, associados à fala e destreza. Tais áreas no Homo habilis ainda eram incipientes ${ }^{11}$.

Os australopitecíneos têm seu registro fóssil mais antigo datado de aproximadamente quatro milhóes de anos (MA). Surgiram no continente Africano, de onde nunca saíram, até seu desaparecimento há cerca de um milhão de anos. Esses novos que surgiram pertencem à mesma família do homem atual, Hominidae, e os extintos pertencem ao gênero Australopithecus (do latim, australo = sul e pithecus = macaco), significando, portanto, macaco do sul, (isso se deve ao fato de o primeiro Australopithecus ter sido descoberto na África do Sul).

Atualmente, são conhecidas sete diferentes espécies de Australopithecus, nomeadamente: A. ramidus (4,4$4 \mathrm{MA}) ; A$. anamensis (4,1-3,9 MA); $A$. afarensisou grácil (3-3,4 MA); A. aethiopicus (2,6-2,4 MA); A. africanus (2,8-2,3 MA); A. robustus (1,8-1,6 MA); A. boisei (1,8960 MA). Apesar de terem diferenças físicas entre eles, há também características comuns que permitem classificá-los a todos, dentro do mesmo gênero, tais como o bipedalismo, a posição ereta, a baixa capacidade craniana, a baixa estatura, entre outras. Desde as primeiras descobertas, diversos antropólogos tentaram explicar o ancestral comum entre os Australopithecus e o homem atual ${ }^{13}$.

O gênero Australopithecus era essencialmente vegetariano e pesava em torno de $50 \mathrm{~kg}^{14}$; sua locomoção bípede ainda era imperfeita - seus espécimes já apresentavam semelhanças na conformação dos ossos pélvicos, extremidades inferiores e articulaçáo entre o crânio e a coluna vertebral, indicando postura ereta, apesar de não ter sido tão perfeita como a do homem moderno ${ }^{15}-\mathrm{e}$ o volume de seu cérebro era pouco maior do que o de um chimpanzé que tem em média $380 \mathrm{~cm}^{3}$. Seu mais conhecido representante arqueológico, com 3,15 milhóes de anos, é Lucy, um exemplar $A$. afarensis feminino adulto, que media em torno de $1,30 \mathrm{~m}$. Como esse animal não sobreviveu, extinguiu-se dando forma a um ser mais complexo social e cerebralmente, culminando no Homo sapiens. Desapareceu por volta de dois milhóes de anos e não deixou descendência de sua espécie evoluiu para outra mais complexa.

Outra herança importante dos Australopithecus foi 
abipedalização, já comentada mais adiante. Além de liberar a mão para maior habilidade, a bipedalização acompanhou-se da neotenia: o fato de que bebês bípedes nascem antes de completar sua formação cerebral e os cérebros crescem fora do processo de formaçấo do feto. Tal evento trouxe inúmeras capacidades, como a de aprendizado contínuo ${ }^{15}$ e a possível redução de algumas capacidades instintivas ${ }^{8}$ sendo necessário mudar sua maneira de se relacionar com o meio.

O Homo habilis (h.h.) trouxe uma contribuição muito importante para a evolução do homem. A tecnologia de fabricação própria (self-madetechnology); quando começa a lascar pedra, para fazer tudo: caçar, tirar o tutano das carcaças, espantar outros animais e afastar grupos rivais, o que, antes de usar tecnologia, seus antepassados não podiam fazer ${ }^{16}$.

Este individuo, com certeza, já superava algumas de suas limitaçóes corpóreas usando tecnologia, talvez seja a etapa em que o cérebro começa a se complexar em direção à workingmemory. Vale lembrar que é a primeira vez que o hominídeo tem o prenome de Homo $^{17}$.

Embora a "tataravó" do h.h., Lucy, uma Australopithecusafarensis, já pudesse andar ereta, o h.h. alcançou mudanças estruturais em sua coluna vertebral, possibilitando importantes mudanças na organização no sistema nervoso central e periférico. Uma grande diferença entre o h.h. e os austrelopitecíneos é o tamanho e o formato do cérebro; enquanto o maior macho de Australopithecus tem o cérebro de no máximo $600 \mathrm{~cm}^{3}$, só as menores fêmeas de h.h. têm esse órgão na medida de $\approx 650 \mathrm{~cm}^{3}$, enquanto os machos têm acima de 800 centímetros cúbicos ${ }^{10}$.

A capacidade diferenciada de inteligência humana não está associada ao tamanho relativo do cérebro-corpo, nem em número de neurônios, nem no potencial de velocidade sináptica, mas, no formato e no desenvolvimento do córtex pré-frontal do ser humano, até então único da evolução. As fases evolucionárias depois do h.h., como Homo dmanisensise Homo erectus ${ }^{14}$ demonstram desenvolvimentos cada vez mais crescentes dessa área cortical. Aparece um início de um córtex pré-frontal, ainda que não muito desenvolvido ${ }^{11}$, com as novas técnicas neuroantropológicas torna-se possível saber em que local nos cranios e em que fase evolutiva do cérebro esta parte do cérebro se desenvolve.
O h.h. mostrou uma habilidade diferenciada através da destreza, a qual afetou profundamente seu comportamento e vida social. A destreza só pode ter sido causada por um crescimento neurológico desta área no córtex. Acredita-se que, tanto essa destreza como o crescimento cerebral, foram profundamente influenciados pela mudança radical na alimentação ${ }^{13}$.

A interessante diferença do $h$.h. é a habilidade motora que ele demonstrava. Era capaz de produzir ferramentas complexas e apresentar capacidade de design, ou melhor, de projeto com base em outros objetos de natureza. Ele manipulava objetos encontrados no meio e os transformava (por exemplo, pedras transformadas em machados). Aself-madetecnology; essa é uma importante diferença que, sem dúvida, pode ser vista como novidade genuína para a evolução do homem. Essa criatura, certamente já desenvolvia um nível de consciência de limitação própria e de capacidade para se superar. Como ele superou vários problemas apresentados pelo meio para sobreviver, apenas com inteligência diferenciada ${ }^{16}$.

Ha efeitos ressonantes evolutivos advindos do uso de tecnologia, que merecem nossa atenção por sua ação transformadora na evolução da cognição humana uma vez que afetam o cérebro- a mão e alimentação ${ }^{17}$.

Esses instrumentos possibilitaram duas coisas importantíssimas ao Homo habilis: a obtenção de alimento diferenciada, a partir da rapinagem e da caça e, consequentemente, maior socialização, elemento fundamental para a aquisição da linguagem ${ }^{18}$.

Essa alimentação proporcionou uma riqueza protéica duas vezes necessária:

- As mudanças na estrutura óssea que estavam acontecendo em sua coluna vertebral ${ }^{13}$ e em suas mãos ${ }^{16}$.

- A mudança estrutural em seu próprio cérebro, que, em nossa opinião, influenciou na aquisição da cogniçáo complexa do homem. Uma mudança cerebral necessitaria de grande quantidade de alimentação e de mudança radical na dieta, o que resultou no desenvolvimento do córtex pré-frontal ${ }^{14}$. Quanto às mãos, assim como no caso da bipedalização, verificou-se uma modificação de anatomia básica dos primatas. O dedo polegar humano é mais longo que no chimpanzé ou gorila e é posicionado ligeiramen- 
te mais afastado dos outros quatro dedos, portanto, em oposição aos demais, possibilitando maior rotação. Significa que o dedo polegar pode ser girado contra os dedos, permitindo pegar objetos de diferentes tamanhos com a mesma eficácia ${ }^{16}$.

Essa sensível alteração anatômica cria amplo espectro de funçôes que os também diferenciam humanos dos macacos, pois nos dá tanto a precisão como a força para agarrar. $\mathrm{O}$ alcance de atividades passíveis de serem executadas pelas mãos humanas é bastante diversificado, pois se possibilitou a utilização de ferramentas como a lança, o machado, as agulhas e a linha; tornou-se possível ninar uma criança, pintar uma obra-prima ou tocar uma música em um piano ${ }^{16}$.

O desenvolvimento da destreza (high-handeness) é associado no cérebro humano ao neocórtex lateral esquerdo, o córtex pré-motor, na parte posterior do córtex frontal esquerdo, próximo e em constante comunicação com a área de Broca por meio do feixe de nervos chamado Fascículo Arqueado ${ }^{19}$.

Como o h.h. tinha uma habilidade diferenciada na destreza, isso só pode ter sido possibilitado por um crescimento neurológico da área de destreza no córtex e uma mutação nas mãos, derivados do bipedalismo. Acredita-se que, tanto essa destreza como o crescimento cerebral, foram profundamente influenciados pela mudança radical na alimentação ${ }^{11}$.

Estudos com símios demonstram que células nervosas específicas dessas áreas cerebrais têm boa absorção de proteínas encontradas em animais como peixe, por exemplo, o que não fazia parte da dieta dos Australopithecus. Uma dieta só pode ser mudada com uso de tecnologia (pesca, caça, cerceamento de animais) ${ }^{14}$.

Essa mudança de dieta teve profunda influência no desenvolvimento cognitivo do homem. "O estudo de crânios de Homo habilis demonstra que o protodesenvolvimento dessas áreas se dá nessa fase da evolução humana. Nos estágios anteriores (Australopithecus), não há espaço ou forma dentro do crânio dessas espécies que demonstrem um desenvolvimento dessas áreas corticais; estudos dos ossos nas cadeias posteriores ao H. habilis ( $H$. dmanisensis e $H$. erectus) demonstram um desenvolvimento maior das mesmas áreas ${ }^{11}$.

A mudança radical de dieta proporcionada pelo uso de tecnologia ocasionou mutação nas estruturas celulares ocorridas no cérebro humano ${ }^{20}$.

Há também o aumento da ingestáo de cálcio de maneira radical, podendo ter afetado a quantidade de ATP (Adenosina trifosfato) e, possivelmente, afetou neurotransmissores à base de potássio. As células do córtex pré-motor apresentam diferentes capacidades de absorção de ATP e proteína 14-3-321 no homem e nos chimpanzés, que poderia fornecer novos recursos de comunicação intracelular. "Sem dúvida, essas mudanças foram fundamentais para o desenvolvimento da área de destreza e linguagem e, consequentemente, da cognição; além disso, outras influentes mudanças no corpo, como estômagos menores, propiciaram uma preciosa reserva de energia para o cérebro. $O$ cérebro é o órgão que mais consome energia, enquanto estômagos vegetarianos, que são sempre relativamente grandes, consumiriam uma energia preciosa, impedindo, talvez, o crescimento cerebral”22.

Além disso, outro fator importante foi proporcionado pela ampliação de variedade na alimentação diferenciada causada pelos instrumentos de pedra: o início da socialização particular do gênero $\mathrm{Homo}^{23}$.

Como se vê fez-se nessa breve introdução uma breve analise das possíveis contribuiçôes da neuroantropologia e pudemos explicar várias mudanças ocorridas nos cérebros dos ancestrais humanos e explicou-se como a neuroantropologia funciona e pode explicar donde, em quais condiçôes certas complexidades e corpúsculos cerebrais surgiram e daí inferir certos comportamentos complexos.

Porém longe de se limitar a isso, a neuroantropologia pode cooperar com diversos aspectos neuroevolutivos, minha pesquisa particular por exemplo pode responder vários aspectos da destreza humana, que me faz capaz por exemplo de digitar no computador esse texto e de forma consciente.

Cita-se como exemplo de uma complexa interação social a rapinagem, na qual o hominídeo obteria ossos deixados ao léu, consumindo o tutano que extraía de dentro deles com o uso de machados de pedra, uma rica fonte protéica que quase nenhum animal tem. Como o h.h. faria para obter os ossos? Ele teria que utilizar uma divisão social de trabalho muito eficiente para que parte do bando distraísse outras espécies de rapinadores enquanto outra parte fugia com os ossos. 
O h.h. teria que pegar várias carcaças recém-mortas por animais maiores e mais perigosos que hienas, como o tigre de dente de sabre. Como? Hoje observamos o comportamento de caça de alguns felídeos que vivem em bando, como os leôes da savana que caçam em bandos como os tigres de dentre de sabre. Os felinos que caçam juntos marcam um território de caça, atacam um bando de mamíferos quadrúpedes que vão beber água, pegando os mais fracos, depois de matar um, se o bando de caçadores for grande, eles abandonam por pouco tempo as primeiras carcaças derrubadas e vão atrás de outro membro do bando. Nesse curto período de tempo, o h.h. agia com extrema inteligência social, enquanto parte do bando vigiava para ver se os caçadores voltavam, outros utilizavam seus machados de pedra para extrair pedaços de carne da caça, numa atitude perigosa e que teria que ser muito rápida, obtendo assim carne fresca o suficiente. No caso de caçadores que caçavam solitários, como a cheeta pré-histórica e o cinogato, cuja habilidade seria capaz de matar um búfalo, mas não de comê-lo inteiro, deixando boa parte da carcaça fresca, confiando no seu território marcado pelo seu cheiro. Entrar no território de um caçador poderoso pode ser extremamente perigoso, mas agindo em bando, com vigia e aumentando sua socialização, o h.h. seria capaz de obter o táo precioso alimento ${ }^{24}$.

O aumento da socialização também se prova pelo ensino das técnicas de caça e rapinagem aos mais jovens das famílias de $h$.h. Isso envolve o ensino de fabricação de instrumentos. $\mathrm{O}$ aprendizado dessa instrumentação era adquirido muito rápido, ainda quando criança, pois os instrumentos oduvaidenses, bem pequenos, que só caberiam em mãos pequenas (de crianças e adolescentes, considerando o tamanho dos fósseis encontrados ${ }^{24}$. Nenhum outro símio tem esta capacidade de aprender a lidar com instrumentos desde filhote. Apenas o chimpanzé mais habilidoso conseguirá manipular instrumentos apenas depois de adulto e bem treinados por humanos, porém, sem capacidade de transformar o objeto as suas necessidades ${ }^{25}$. Crê-se que o fator de socialização foi muito importante na formação do processo cognitivo.

A neuroantropologia observa ainda a relação intracerebral entre destreza e linguagem e que as estruturas cerebrais que são responsáveis pela linguagem (área de Broca e de Wernicke) e destreza (neocórtex lateral esquer- do) se desenvolvem juntas na criança ${ }^{22}$.

Já deu para perceber a importância da neuroantropologia para a compreensão de certos aspectos complexos da cognição humana, porem ela pode ajudar em vários outros aspectos a saber:

Tem a capacidade de estudar a neuro-evolução do desenvolvimento das formas de socialização e o papel do sistema nervoso, o sistema sono-vigilia, o aprendizado, o sistema medo estudando as funçóes evolutivas da Amigdala, do Hipocampo, do Fórnix e Giro Parahipocampal, do Tálamo e Hipotálamo, do Giro Cingulado, do tronco cerebral e do córtex, chegando até o neo córtex frontal e suas relaçóes com o medo, o stress e a ansiedade ${ }^{25}$.

Por exemplo, pode estudar em que ponto e condiçóes ambientais surgiram nos mamíferos os gânglios Basais, ou a absorção nicotínica em busca pelo sistema prazer-recompensa ${ }^{26}$.

Tem os meios de estudar as estruturas e em que condiçôes surgiram a linguagem ${ }^{8}$. Os sistemas vivos em geral podem ser entendidos como sistemas de comunicação ${ }^{14}$. Os seres humanos alimentam-se não apenas de matéria, mas também de informação, trocando-as entre si, com outros seres vivos e com o meio ambiente ${ }^{23}$.

As formas de comunicações dos demais seres vivos, como o canto de uma espécie determinada de pássaro no acasalamento, possuem e produzem sentido, mas, mesmo quando apresentam alguma possibilidade de recombinação e modulação, como nos pássaros mais admirados pelos seres humanos por seu canto ou capacidade de imitação, são formas de comunicação bastante rígidas de cada espécie em que - e apenas para um reduzido número de espécies - a variabilidade permissível ao indivíduo restringe-se a poucas séries de combinaçóes ${ }^{14}$.

Alem do mais, não há função de referência ou critérios semânticos de relevância nas formas de comunicação de outros seres vivos, o que nos faz hesitar em classificá-las como linguagem, porem a neurodestreza de gritos, guinchos, uivos e outros sons de comunicação, sobretudo sobre situação de medo, stresse, acasalamento pode ser entendido como uma proto-linguagem ${ }^{26}$.

A linguagem humana ultrapassa a fronteira do simples em direçáo ao hipercomplexo: constitui um sistema de infinitas combinaçôes e não somente mero veículo de transmissão de informaçóes; tanto reflete o real quanto 
por si mesma cria outras realidades, especificamente humanas, como a arte, o sonho e a música. isso depende de presença de interlocutores e de estruturas específicas no cérebro e no corpo $^{23}$.

Pode estudar as questóes de cultura e diferenciação cerebral em questôesde gênero em face dos dados de que cérebros de homem e mulher e homossexuais são diferentes ${ }^{27}$.

Podem-se analisar as questôes de saúde mental publica, com vistas a dar um melhoramento das instituiçóes de atendimento mental.

Pode analisar o imaginário popular de pacientes com problemas mentais destruindo preconceitos e estereótipos da sociedade em relação aos pacientes mentais.

Pretende se integrar a antropologia da saúde que tem abordado ofenômeno da doença em duas perspectivas: como ele éexperimentado pelos doentes e como é a experiência dos profissionais de saúde ${ }^{1}$ e que procura construir, na perspectiva da antropologia da saúde e dadoença, conceitos adequados à compreensão do fenômeno doença, tais como doença-sujeito (a illness ou a experiência subjetiva da doença), doença-sociedade (a sickness, que designa os comportamentos socioculturais conectados com a doença em uma dada sociedade) e doença-objeto (tal como apreendida pelo saber biomédico).

A neuroantropologia pode ajudar a compreender tanto esses sentidos existenciais como se especializar e estudar a questão dosickness, illness and disease tanto do ponto de vista subjetivo, do cultural, e também no que se especifique as doenças de base neurológica.

Pode ajudar tremendamente a psiquiatria e a psicologia, que deve em seus aspectos de tratamento psicoterápico que deve compreender todos os aspectos culturais e imaginários relativos ao cérebro e não apenas medicar.A neuroantropologia pode cooperar decididamente com a psicologia evolutiva. Ainda poderá ajudar a humanizar o tratamento tradicional psicoterápico a exemplo de Nise da Silveira.

A neuroantropologia criminal pode compreender os aspectos culturais e cerebrais da violência e do crime, bem como pesquisar em que momento da evolução surgiram os aspectos neurológicos de violência, sexo e estruturas inibitórias da violência do cérebro ${ }^{28}$.

Pode estudar a neuro-evolução dos sistemas perceptivos, das estruturas perceptivas nos antepassados dos seres humanos e fornecer explicaçóes para os fenômeno perceptivos que se encontram na evoluçáo ${ }^{29}$.

Ainda pode fornecer dados que facilitem o processamento e a modelagem matemática de seres que não mais existem os ancestrais dos seres humanos para fornecer explicaçóes e modelagens de explicaçóes computacionais cognitivas ${ }^{30}$.

Pode estudar a relação que ha entre cérebro, êxtase religioso, entre diversas constataçóes de neurocientistas que pesquisam o êxtase religiosos, a mais intrigante foi a diminuição da atividade do lobo parietal superior, uma área na parte alta do cérebro que influencia nossa orientação espacial e de tempo. Sabe-se que Utilizando ressonância magnética funcional, prova-se que partes do córtex pré-frontal e do córtex cingulado anterior, podem ser alteradas em certos rituais causando sensaçóes psicofísicas $^{31}$.

Dentro deste viés da religião pode pesquisar e cooperar com o estudo de psicoses raras como a Síndrome de Jerusalém ${ }^{31}$. Ainda nesse viés pode cooperar com o estudo da sensação de paz que traz a prece e os fenômenos neuro - fisiológicos que podem trazer a meditação, ou o fenomeno de glossolalia ${ }^{31}$. Pode estudar o fenômeno histérico conhecido vulgarmente como possessão demoníaca e suas causas cerebrais.

$\mathrm{Na}$ história da Humanidade os sintomas de alteraçóes no sistema nervoso foram comparados à casos de possessão demoníaca e efeitos de feitiçaria ${ }^{29}$. Segundo Freud $^{33}$ são manifestaçôes de sintomas histéricos, onde pode-se observar uma série de distúrbios psíquicos: alteraçôes no curso e na associação de idéias, inibições na atividade da vontade, exagero e repressão de sentimentos.

Ainda pode estudar dentro dos fenômenos religiosos o processo de oração em relação a Psiconeuroimunologia $^{32}:$ mostra que a meditação e a oração é capaz de desempenhar papel importante na resistência das chamadas doenças infecciosas, que até então eram consideradas como "estritamente fisiológicas". Sendo assim, todo uma imensa área da medicina foi aberta para se estudar os estímulos psicológicos destas doenças,assim como é sabido que o estresse afeta o sistema imunológico ${ }^{31}$.

Pode ajudar a estudar a parte neuro-social do uso de tóxicos e álcool ajudando tremendamente no estudo relativo aos danos cerebrais. Estudando ainda os fenô- 
menos da drogas pode explicar certos fenômenos sociais por exemplo, alguns antropólogos defendem que as primeiras idéias religiosas surgiram do consumo de cogumelos alucinogenos pelos povos antigos ${ }^{33}$. Dentro desse levantamento, crê-se que o papel da neuroantropologia se fez fundamental, inferindo através das formas craniais as capacidades cognitivas de cada um dos antepassados.

É analisando a totalidade dos ancestrais humanos que se pôde observar como eles puderam vencer as dificuldades que o meio lhes apresentava, significando desenvolvimento de inteligência com criatividade, logo vê como um ensaio neuroantropológico pode explicitar do porquê um macaco frágil pode se transformar no homem com todas suas complexidades cerebrais, culturais, emocionais e mentais.

A neuroantropologia pode cooperar para a compreensão do funcionamento cerebral humano e devser revista com mais atenção pelas ciências cognitivas uma vez que as respostas para muitas perguntas a vezes se encontram no passado, tempo esse que a neuroantropologia busca responder quando se trata do cérebro.

\section{REFERÊNCIAS}

1.Laplantine F. Antropologia da Doença. 2a ed. São Paulo: Martins Fontes, 2002, 282p.

2.Larsen, Clark Spencer. Essentials of Physical Anthropology: Discovering Our Origins. W.W. Norton, New York. 2010, 399 pp

3.Couser TG. Essays of Awkenings, the Cases of Oliver Sacks: The Ethics of Neuroanthropology, Indiana IL, monograph of PhD. Indiana University, programof medical ethicsresearch, 2001, 78p.

4.Sacks O. Tio Tungstênio: Memórias de uma infância química, Cia. Das letras 1999 .

5.Berg D, Holtzmann C, Riess O. 14-3-3 Proteins in the nervous system. Nature Rev Neurosc2003;4:752-62.

http://dx.doi.org/10.1038/nrn1197

6.Amira K. Finite element analyses of ankylosaurid dinosaur tail club impacts. Multifaceted software platform for visualizing, manipulating, and understanding Life Science and bio-medical data coming from all types of sources (Endereçona Internet). VisageImagingGmbHCo. (atualizado em 2010, Acessado em 10/2010). Disponível em: http://www.vsg3d.com/sites/default/files/related/ fei_sh_amira_ls.pdf.

7.Dardon U, Souza RS. Bergqvist LP, Abranches CTS (Endereço na Internet). Modelagem 3D e suas aplicaçóes na pesquisapaleontológica (atualizado em: 12/11; Acessado em: 03/12). Disponível em: https://www.academia. edu/1933057/Modelagem_3D_e_suas_aplicacoes_na_pesquisa_paleontologica 8.Sanvito L. O cérebro e suas vertentes. São Paulo: Panamed, 1989,173p.

9.Corballis MC. The Lopsided Ape: Evolution of Generative Mind. New York:
Oxford Press Inc., 1993,184p.

10.Mithen S. A Pré-história da Mente: uma busca da arte da religião e da ciência. São Paulo: Ed. UNESP, 2003, 426p.

11.Falk D. Braindance. New York: Henry Holt and Company. Inc., 1992, 502p. 12.Buss DM, Reeve HK.Evolutionary psychology and developmental dynamics. Psychol Bul 2003;129:848-53.

http://dx.doi.org/10.1037/0033-2909.129.6.848

13.Godoy JA. El Origen del Hombre. Madrid: Ediciones Palabra, 1987,146p. 14.Wills C. The Runaway Brain: The evolution of human uniqueness. New York: Harper Collins publisher. 1992, 201p.

15.Johanson D, Shreeve J. O Filho de Lucy: a descoberta de um ancestral humano. Rio de Janeiro: Bertrand Brasil, 1998, 432p.

16.Susmam RL. Hand function and tool behavior in early hominids. J Hum Evol 1998;35:23-46.

http://dx.doi.org/10.1006/jhev.1998.0220

17.Richardson JT. Envolving concepts of working memory.In: Richardson J, Engel R, Hasher L, Logue R, Staltzfus E, Zacks R (Orgs.). Working memory and human cognition. New York: Oxford Press, 1996, p.6-30.

18. Bronowski J. A escalada do homem. 4aed. São Paulo: Martins Fontes, 1969, 442p.

19.Kandel E, Schwartz JH, Jessel T. Fundamentos da Neurociência e do Comportamento. Rio de Janeiro: Guanabara e Koogan, 1995, 591p.

20.Pereira Jr. A. Questôes Epistemológicas de Neurociência Cognitiva(Tese). Botucatu: Universidade Estadual Paulista “Júlio de Mesquita Filho”2001,129p. 21.Blanchard DC. Blanchard RJ. Rodgers RJ. Risk assessment and animal models of anxiety. In : Olivier B, Mos J, Slangen JS (Eds.). Animal models in Psychopharmacology. Annu Rev Psychopharmal 1991;23:283-91.

22.Greenfield PM. Language, tools, and brain: the ontogeny and phylogeny of hierarchically organized sequential behavior. Beh Brain Sci 1991;14:531-51. http://dx.doi.org/10.1017/S0140525X00071235

23. Costa OBR. Sobre as causas evolutivas da cognição humana (Tese). Marilia: Faculdade de Filosofia e Ciências, Universidade Estadual Paulista, 2009, 192p. 24. Foley R. Os humanos antes da humanidade: uma perspectiva evolucionista. São Paulo: Ed. UNESP, 2003, 294p.

25.Deacon TD. The Symbolic Species: The co-evolution of language and the brain. New York: WW Norton \& Company Inc. Publications, 1997, 527p.

26.Ribas GC. Considerações sobre a evolução filogenética do sistema nervoso, o comportamento e a emergência da consciência. Rev Bras Psiquiatr 2006;28:226-38.

http://dx.doi.org/10.1590/S1516-44462006000400015

27. Moir A, Jessel D. Brain Sex: The Real Difference Between Men and Women.New York: Dell Publishing, 1993, 256p.

28.De Waal FBM. Evolutionary Ethics, Aggression, and Violence: Lessons from Primate Research. J Law Med Ethics 2004;32:18-23.

http://dx.doi.org/10.1111/j.1748-720X.2004.tb00444.x

29.Vignaux G. As Ciências Cognitivas - Uma Introdução. Lisboa: Instituto Piaget, Colecção Epistemologia e Sociedade, 1995, 361p.

30.Penrose R, Gardner M. A Mente Virtual: sobre computadores, mentes e as leis da física. Lisboa:Gradiva, Coleção Ciência Aberta, 1997, 606p.

31.Persinger MA. religious and mystical experiences as artifacts of temporal lobe function: a general hypothesis. Percep Motor Skills 1983;57:1255-72. http://dx.doi.org/10.2466/pms.1983.57.3f.1255

32. Webster JI, Tonelli L, Sternberg EM.Neuroendocrine regulation of immunity. Annu Rev Immunol 2002;20:125-63.

http://dx.doi.org/10.1146/annurev.immunol.20.082401.104914

33.Freud S,Breuer J. Estudos sobre a histeria. In S Freud. Edição standard brasileira das obras psicológicas completas de Sigmund Freud, vol 2. Rio de Janeiro: Imago, 1976, 350p. 